\title{
Sensory and Chemical Analyses of Monovarietal Olive Oils from Lake Garda (Northern Italy)
}

D. Tura, O. Failla and D. Bassi

Dipartimento di Produzione Vegetale

Università degli Studi di Milano

Via Celoria, 2 - 20133 Milano - Italy

\author{
A. Serraiocco \\ Istituto Sperimentale per l'Elaiotecnica \\ Contrada Fonte Umano \\ 65013 Città S. Angelo (PE) - Italy
}

Keywords: aroma, cultivar, Olea europea L., polyphenols, volatile compounds

\begin{abstract}
The qualitative description of an olive oil should be based not only on chemical and physical analyses but also on sensory evaluation. The present study was designed to evaluate by sensory analysis the monovarietal oils from olive accessions in a germplasm collection in northern Italy's Lake Garda area. Relationships of chemical and sensory evaluation were studied by correlation and multiple regression analysis. Olive accessions were successfully classified by oil sensory profile. A rather good agreement among sensory traits and chemical analysis of volatile compounds and polyphenols was found.
\end{abstract}

\section{INTRODUCTION}

The qualitative description of an olive oil should be based not only upon chemical and physical but also on sensory analysis so as to show defective and/or appealing flavour and aroma traits. Recent research supports the use of sensory analysis in oil evaluation and the inter-relations of volatile compounds, polyphenols and sensory attributes. 'Green' flavours of olive oil are produced from polyunsaturated fatty acids through a cascade of enzymatic reactions known as the 'lipoxygenase pathway' (Olias et al., 1993; Angerosa et al., 1997). More than sixty volatile compounds have been identified by GC-MS in virgin olive oils (Kiritsakis, 1998) and sensory attributes were assigned (Morales et al., 1995; Aparicio et $a l .$, 1995). The present investigation was aimed at evaluating monovarietal oils from olive accessions in order to consider their qualitative potential by sensory analysis and to correlate the sensory profile to the chemical composition of the volatile and polyphenol compounds.

\section{MATERIALS AND METHODS}

Olives from sixteen olive accessions, local cultivars and those from elsewhere in Italy, from a germplasm collection located at Puegnago (Lake Garda, northern Italy) were harvested in 1998 (Figure 1). Eight-ten kgs of olives per accession were processed by a standard discontinuous procedure; the maturity index was evaluated before oil extraction after Uceda (1983). The olives were crushed with an inox hammer crusher, malaxed for $30 \mathrm{~min}$ at $28^{\circ} \mathrm{C}$ and the oil was extracted by hydraulic press (max 200 bars) and separated by centrifugation at $2000 \mathrm{~g}$. Volatile and phenolic compounds were analysed after Angerosa et al. (2000). Sensory evaluation was performed by a trained panel according to a parametric non-structured card which included olfactory, gustatory and tactile notes (Angerosa et al., 2000); the card was developed by the panel on the basis of their previous experience. For each descriptor, the length of the segment marked by the panellist was recorded as intensity measure of the sensory note. The data from each panellist were standardised by normal scores. The statistical significance was verified by Duncan test based on the ANOVA model. Cluster analysis by the square Euclidean distance and the average linkage between groups was performed. Normal distribution of the chemical parameters was checked by the Kolmogorov-Smirnov test. Relationships between chemical and sensorial analyses were studied by correlation analysis and multiple regression models based on the stepwise method. Data were processed by SPSS for Windows v. 9.0 statistical package. 


\section{RESULTS AND DISCUSSION}

The maturity index ranged from 1.4 to 4.5 , corresponding to green-yellowish to black-skinned fruits with flesh not completely darkened. Within this ample range of maturity stages no correlation were detected by comparing maturity indexes, sensorial notes and polyphenols, while a negative relation with hexan-1-ol was found $\left(-0.58^{*}\right)$.

Only the 'sweet' note, out of sixteen, did not show significant differences among the monovarietal oils. Such sensory traits as 'lawn', 'leaf', 'fruity', 'bitter', 'pungent' and 'astringent' were detected in almost all oils, others like 'flowers', 'artichoke', 'walnut' and 'hay' were detected only in some, and 'banana', 'tomato', 'almond', 'apple', 'butter' only in a few oils. Accessions were clustered in seven groups according to the sensory profiles of their oils (Figure 1) as follows: Group 1, characterised by green sensorial notes (tomato, lawn, fruity), included oils from four local accessions and 'Maurino'. Group 2, related to group 1, included only the oil from accession 1 of 'Casaliva', a 'Frantoio'related cultivar; this oil was characterised for the 'green' notes together with other flavours and tastes. However, it should be noted that this accession, unlike 'Casaliva 2', was harvested at a riper stage. Group 3 linked two accessions, 'Baia' and 'Regina', with sensorial different oils, which were paired by the 'bitter', 'pungent' and 'flowers' notes. Group 4 included only one accession, 'Rossanello', with very unique sensorial notes. Group 5 linked 'Frantoio' and 'Leccino', oils that were characterised by 'hay' and 'green ' sensory traits. Group 6 linked four local accessions 'Favarol 2', 'Less', 'Mignol 2' and 'Mitria' characterised by 'flowers' and unique notes. Group 7 included only 'Pendolino', with 'walnut', 'almond' and 'artichoke' notes.

The following relationships of chemical to sensory analyses were detected (Table 1). The 'flower' attribute was correlated by simple correlation to two volatile compounds linked to 'sweet' flavour, ethyl acetate and 3-methylbutanal; by multiple regression a possible secondary contribution of octan-1-ol and hexanal was detected. 'Apple' flavour was correlated to four volatile compounds out of which trans-2-pentenal is known to express the 'apple' aroma; it was also correlated to cis-3-hexen-1-ol, a 'banana' flavoured compound and to ethanol and to 2-methylbutanal. By multiple regression, only cis-3hexen-1-ol and ethanol entered the model. However, it should be noted that the 'apple' attribute was detected only in two oils ('Baia' and 'Maurino') so, even if significant, the statistical models should be carefully evaluated. 'Pungent' flavour was correlated to $2-$ methylbutanal, 1-penten-3-one and total polyphenols. Both 1-penten-3-one and hexenal-1ol fitted the multiple regression model with positive and negative effects, respectively. However, it should be noted that 2-methylbutanal was correlated to 1-penten-3-one $(0.70 * *)$ and to total polyphenols $(0.54 *)$, consequently the correlation and multiple regression results have to be considered as ambiguous. 'Astringent' flavour was correlated to 1-penten-3-one, whose multiple regression model also included trans-2pentenal, with negative effect, and 2-methyl-propan-1-ol and total polyphenols, with a positive effect. 'Lawn' flavour was correlated to 1-penten-3-ol, a molecule associated to 'wet soil' flavour. 'Leaf' flavour was correlated to trans-2-exenal, a 'green' flavoured compound; $n$-octane entered the multiple regression model with a negative effect. 'Banana' flavour was correlated to cis-2-penten-1-ol, which is known as a bananaflavoured compound; polyphenols and 1-penten-3-one, the latter with a negative effect, also fit the multiple regression model. 'Bitter' taste was correlated to total polyphenols, as expected, and hexanal, a 'green' flavoured compound, fits the multiple regression model. 'Butter' flavour resulted correlated to $n$-octane.

\section{CONCLUSIONS}

Sensory analysis discriminated among oils, as reported by others (Aparicio and Morales, 1995; Morales et al., 1995; Aparicio et al., 1997). Results were validated by a general agreement among sensory traits and chemical analysis of volatile compounds and polyphenols. A better agreement was found for 'green', 'flower' and 'bitter' notes while some ambiguities and doubtful results were detected for 'apple', 'astringent' and 'pungent' notes. Some sensorial attributes i. e. 'fruity', 'artichoke', 'walnut husk', 'green 
tomato', 'hay' and 'sweet', did not correlate with chemical analysis. The role of genotype in oil sensorial characteristics was not a simple consequence of olive maturity stage, although, for each accession, changes in sensory profiles should be expected as ripening evolves.

\section{ACKNOWLEDGEMENTS}

Research funded by EU Commission, Reg. CE 2430/97 in co-operation with the Agriculture Department of Lombardy Region, Italy.

\section{Literature Cited}

Angerosa F., Di Giacinto L. and D'Alessandro N., 1997. Quantitation of some flavour components responsible for the 'green' attributes in virgin olive oils. J. of High Resolution Chrom. 20: 507-510.

Angerosa F., Mostallino R., Basti C., Vito R., 2000. Virgin olive oil odour notes: their relationships with volatile compounds from the lipoxygenase pathway and secoiridoid compounds. Food Chemistry 68: 283-287.

Aparicio R. and Morales M. T., 1995. Sensory wheels: a statistical technique for comparing QDA panel-application to virgin olive oil. J. Sci. Food Agric. 67: 247-257.

Aparicio R., Morales M. T. and Alonso V., 1997. Authentication of European virgin olive oils by their chemical compounds, sensory attributes, and consumers' attitudes. J. Agric. Food Chem. 45: 1076-1083.

Kiritsakis A. K., 1998. Flavour components of olive oil: a review. J. Am. Oil Chem. Soc. 75, 6:673-681.

Morales M. T., Alonso M. V., Rios J. J. and Aparicio R., 1995. Virgin olive oil aroma: relationship between volatile compounds and sensory attributes by chemometrics. J. Agric. Food Chem. 43: 2925-2931.

Olias J. M., Peres A. G., Rios J. J. and Sanz L. C., 1993. Aroma of virgin olive oil: biogenesis of the 'green' odour notes. Journal Agric. Food Chem. 41: 2368-2373.

Uceda M., 1983. Factores que influyen en la calidad del aceite de oliva. Simp. Expoliva 83, Jaen $(\mathrm{E})$ 


\section{$\underline{\text { Tables }}$}

Table 1. Linear correlation and multiple regression for comparison of each sensorial note with volatile compounds and total polyphenols of the 16 monovarietal oils.

\begin{tabular}{|c|c|c|c|}
\hline $\begin{array}{l}\text { Sensory } \\
\text { Note }\end{array}$ & $\begin{array}{l}\text { Chemical compound } \\
\text { (linear correlation: } \mathbf{r} \text { ) }\end{array}$ & \multicolumn{2}{|l|}{ Multiple regression $\left(\mathbf{r}^{2}\right)$} \\
\hline Flowers & $\begin{array}{ll}\text { ethyl acetate } & (0.54 *) \\
\text { 3-methylbutanal } & (0.68 * *)\end{array}$ & \multicolumn{2}{|c|}{$-1.2+0.79 * 3$-methylbutanal+0.81*octan-1-ol+0.09*hexanal $(0.88 * *)$} \\
\hline Apple & $\begin{array}{l}\text { 2-methylbutanal }(0.68 * *) \\
\text { ethanol } \quad\left(0.80^{* *}\right) \\
\text { trans-2-pentenal }(0.73 * *) \\
\text { cis-3-hexen-1-ol }(0.79 * *)\end{array}$ & $-0.30+0.005 *$ ethanol+0.006*cis-3-hexen-1-ol & $(0.97 * *)$ \\
\hline Pungent & $\begin{array}{l}\text { 2-methylbutanal }\left(0.55^{*}\right) \\
\text { 1-penten-3-one }\left(0.63^{* *}\right) \\
\text { total polyphenols }\left(0.54^{*}\right)\end{array}$ & $-0.07+0.06 * 1$-penten-3-one- $0.02 *$ hexan- 1 -ol & $\left(0.78^{* *}\right)$ \\
\hline Astringent & 1-penten-3-one & $\begin{array}{l}-0.50+0.08 * 1 \text {-penten-3-one- } 1.9 * \text { trans-2-pentenal+ } \\
+0.44 * 2 \text {-methylpropan- } 1 \text {-ol }+0.002 * \text { total poliphenols }\end{array}$ & $(0.94 * *)$ \\
\hline Lawn & 1-penten-3-ol & $-0.64+0.09 * 1$-penten-3-ol & $(0.54 *)$ \\
\hline Leaf & trans-2-hexenal $\quad\left(0.53^{*}\right)$ & $-0.003+0.003 *$ trans -2 -hexenal $-0.13 * n$-octane & $(0.70 * *)$ \\
\hline Banana & cis-2-penten-1-ol $\left(0.66^{* *}\right)$ & $\begin{array}{l}-0.65+0.03 * \text { cis-2-penten- } 1-\text { ol }+0.005 * \text { total poliphenols+ } \\
-0.04 * 1 \text {-penten-3-one }\end{array}$ & $(0.92 * *)$ \\
\hline Bitter & total polyphenols $(0.74 * *)$ & $-1.34+0.007 *$ total poliphenols $+0.17 *$ hexanal & $(0.88 * *)$ \\
\hline Butter & $n$-octane & $-0.2+0.10 * n$-octane- 0.002 ethanol & $(0.77 * *)$ \\
\hline
\end{tabular}

\section{$\underline{\text { Figures }}$}

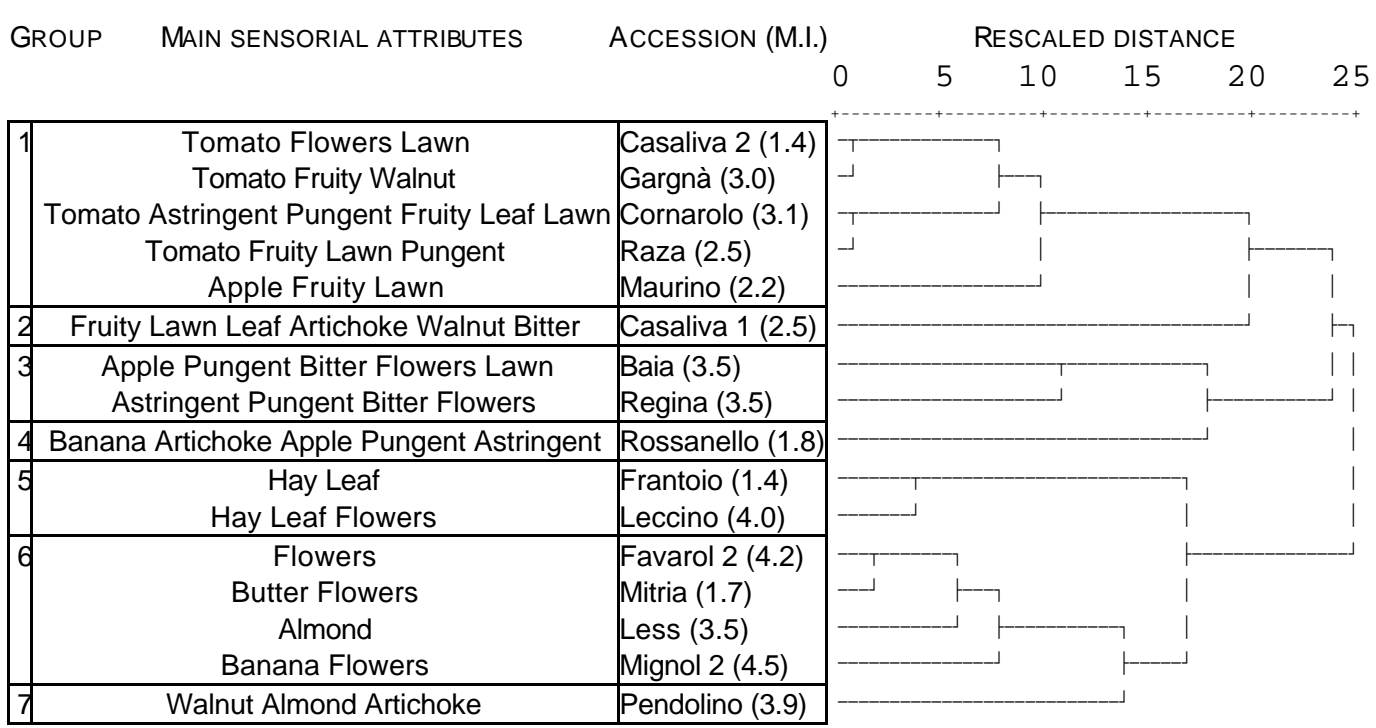

Fig. 1. Clustering according to monovarietal oil sensorial profiles; for each accession, maturity index (M.I.) and the main sensorial notes are listed. 